\title{
PSA Response to Lenalidomide
} Therapy in a Pre-Treated Patient with Metastatic Prostate Cancer Refractory to Hormones and Chemotherapy: A Case Report

\author{
Joan Manel Gasent Blesa ${ }^{a} \quad$ Miguel Peris Godoy ${ }^{b}$ \\ María Fonfría Esparcia ${ }^{a}$ Sara Blasco Molláa \\ Balbino Mancheño Magán ${ }^{c}$ José Miguel Sempere Ortells ${ }^{d}$ \\ José Luis Sánchez ${ }^{\mathrm{e}}$ \\ Departamentos de ${ }^{a}$ Oncología Médica y ${ }^{b}$ Medicina Interna, Hospital de Dénia, \\ Marina Salud, Dénia, Departamentos de 'Química Orgánica y Inmunología, \\ Universidad de Alicante, Alicante, y ${ }^{\mathrm{e}}$ Departamento de Ética, Universidad \\ Católica de Valéncia, Valéncia, España
}

\section{Key Words}

Hormone-resistant prostate cancer · Prostate serum antigen · Lenalidomide

\begin{abstract}
Hormone-resistant prostate cancer (HRPC) occurs when prostate cancer is no longer responsive to hormone therapy. Treatment options are limited, and there is a clear necessity for therapies that improve outcome. Preclinical and clinical evidence supports the role of the immunomodulatory agent lenalidomide in HRPC. In this paper, we report that lenalidomide showed antitumoral activity in a patient with HRPC and bone metastases pre-treated with chemotherapy, decreased the PSA level and improved the patient's health status for the first 5 months. It is important to emphasize that it was not associated with hematologic toxicity.
\end{abstract}

\section{Introduction}

Prostate cancer is the most common cancer and the second leading cause of cancer death in men [1]. Androgen deprivation therapy is the treatment of choice in patients with advanced metastatic disease, although progression typically occurs within 1-2 
years of initial response [2,3]. Secondary hormonal therapy is an option in some patients; however, most neoplasms ultimately progress to a situation of androgenindependent growth, namely hormone-resistant prostate cancer (HRPC), androgenindependent prostate cancer or, recently, castration-resistant prostate cancer.

Clinical manifestations include rising PSA (prostate serum antigen) concentration, bone metastases, substantive pain, and soft-tissue/lymph node metastases [4]. Some forms of HRPC treatment are systemic radiation therapy, chemotherapy, immunotherapy and estrogen therapy. However, outcomes in HRPC are very poor and therefore novel agents are needed to improve the treatment of this condition. Many approaches, such as drugs that target specific pathways involved in cell signaling, proliferation, apoptosis, immune modulation and angiogenesis, are currently under investigation to improve survival benefit.

Lenalidomide is a thalidomide analog and also known as a member of the so-called immunomodulatory drugs (IMiDs) with immunomodulatory and antiangiogenic properties. In preclinical studies, lenalidomide demonstrated antitumoral activity, inhibiting hypoxia-induced factor- $1 \alpha$ expression by endothelial cells and epithelial tumor cells, including prostate cells [5], and an increase in PC-3 prostate cancer cell apoptosis with monotherapy or in combination with docetaxel [6]. Using in vitro and in vivo models of prostate cancer, lenalidomide inhibited growth factor-induced invasion and produced synergistic effects in combination with docetaxel that slowed tumor progression [7]. The few published reports about the use of lenalidomide alone or in combination in HRPC patients [8-17] show clear evidence of its clinical antitumoral activity in this disease. In this paper, we demonstrate that lenalidomide not only has antitumoral activity but also has no associated hematologic toxicity.

\section{Case Report}

In this paper, we discuss the case of a 65-year-old male patient diagnosed in August 1999, by transurethral resection of the prostate, with a Gleason 6/10 prostate adenocarcinoma. His past medical history included renal clear cell adenocarcinoma of both kidneys and constipation treated with lactulose. The serum PSA at the time of diagnosis was elevated to $19.7 \mathrm{ng} / \mathrm{ml}$ (normal range 0.0 4.0). Radiotherapy and combined androgen blockade (CAB) therapy was initiated, comprising luteinreleasing hormone analog (Zoladex) and bicalutamide $50 \mathrm{mg}$ daily (table 1). The patient remained asymptomatic with a low PSA level for 5 years (PSA nadir $0.1 \mathrm{ng} / \mathrm{ml}$ ). In January 2008, biochemical and bone progression was diagnosed with an increased PSA of $12 \mathrm{ng} / \mathrm{ml}$; bone metastases were detected by bone and CT scans. A similar scheme of hormonal therapy with CAB was administered. The patient was at castration testosterone levels $(<50 \mathrm{ng} / \mathrm{ml})$. However, 3 months later, his PSA rose again to $37 \mathrm{ng} / \mathrm{ml}$.

In April 2008, the patient was referred to our department with HRPC with bone-only metastases. The patient received a third hormonal therapy with cyproterone acetate for 2 months, but biochemical progression was detected with a new increase of PSA to $64 \mathrm{ng} / \mathrm{ml}$. Subsequently, docetaxel-prednisone-based chemotherapy was started, but the patient's PSA level rose again after an initial drop (64-12-38-57 ng/ml); bone and CT scans showed bone-only metastases. In October, second-line chemotherapy with oxaliplatin and capecitabine on a compassionate-use basis was administered, but after 3 cycles of treatment, PSA level was $233 \mathrm{ng} / \mathrm{ml}$. In November 2008, this therapy was replaced by treatment with fulvestrant for compassionate use and, after the first month PSA level returned to $32 \mathrm{ng} / \mathrm{ml}$. However, in March 2009, his PSA value was higher than $300 \mathrm{ng} / \mathrm{ml}$. Sunitinib was proposed for compassionate use. After being treated for 5 months with sunitinib (50 mg daily on days 1-4, given every 42 days), serum PSA level rose to $749 \mathrm{ng} / \mathrm{ml}$. Soon thereafter, in August 2009 , the patient began treatment with vinblastine-Adriamycin-estramustine and ketoconazole, 
which was discontinued after the third cycle given the clinical deterioration associated with more intense pain (initial PS 1; final PS 2) and increased levels of serum PSA (1,146 ng/ml). In October, the patient received antalgic radiotherapy for bone metastases.

A new line of treatment with lenalidomide $25 \mathrm{mg} /$ day for compassionate use together with analgesic agents was administered in November 2009. Concomitant analgesic medication for bone pain consisted of ibuprofen $600 \mathrm{mg} / 8 \mathrm{~h}$, morphine sulfate $10 \mathrm{mg}$ for rescue and fentanyl patches that were discontinued in January 2010. Hematological toxicity was assessed every 2 weeks and PSA monthly. The patient responded well to lenalidomide therapy, PSA level markedly declined to 391 $\mathrm{ng} / \mathrm{ml}$ and no hematological or cutaneous adverse events were documented; similar hemoglobin levels were maintained before and after lenalidomide treatment (10.4-11.7 g/dl). The patient regained the ability to walk over $7 \mathrm{~km}$ daily, maintaining his lifestyle, and he improved his general performance status until April 2010, when fentanyl patches were reintroduced and his PSA level rose to $422 \mathrm{ng} / \mathrm{ml}$. In May 2010, an increased PSA level of $893 \mathrm{ng} / \mathrm{ml}$ was accompanied by clinical worsening due to the evolution of the disease, and therapy was suspended.

After that, Estracyt (estramustine) $140 \mathrm{mg} / 12 \mathrm{~h}$ was started but no response was obtained; PSA level in July 2010 was $>5,000 \mathrm{ng} / \mathrm{ml}$, and bone and CT scans revealed lymph node, liver and lung metastases. The progressive deterioration of the patient's health led to hospital admission and death in October 2010.

\section{Discussion}

Proliferation, angiogenesis and evasion of immune surveillance are important pathways by which HRPC progresses. Based on antiangiogenic and antitumoral properties of IMiDs, we may highlight thalidomide and lenalidomide among the new agents used for treating HRCP. It has been described that lenalidomide inhibits tumor necrosis factor- $\alpha$ production, diminishes levels of VEGF and basic fibroblast growth factor, stimulates $\mathrm{T}$ cells and hinders angiogenesis. It also promotes apoptosis in malignant cells. The antitumoral activity of lenalidomide is approximately 5,000 times more potent than thalidomide in animal models, and, furthermore, it has the additional advantage of being associated with a better toxicity profile.

In fact, preliminary studies suggest that lenalidomide may have clinical activity in patients with metastatic castration-resistant prostate cancer [16, 17]. Nevertheless, published data about the use of lenalidomide in HRPC are rare so far, particularly in chemotherapy pre-treated patients. All of the data have shown clear evidence of antitumor activity of lenalidomide alone $[13,14]$ or in combination with docetaxel $[9$, 12], paclitaxel $[10,15]$, ketoconazole [11] or GM-CSF [8] in metastatic HRPC patients. Responses described in these studies are promising with regard to survival advantage.

According to our experience, the patient described here, pre-treated with chemotherapy, showed favorable response to lenalidomide therapy for 5 months improving his general health status and quality of life, even discontinuing fentanyl administration for 4 months. It is significant to note that PSA levels declined, and disease response and pain reduction during lenalidomide administration was not accompanied by any toxicity. Hematological tests did not show alteration in hemoglobin levels, and the patient did not experience cutaneous adverse effects. This observation provides an additional benefit and suggests that lenalidomide may be an attractive drug because of its antineoplastic activity and low side effect profile. The evolution of the disease with the appearance of metastases led to worsening of the clinical situation of the patient. 
The prognosis of prostate cancer is mainly determined by the presence or absence of metastases [18]. In our patient, the development of bone, lymph node, liver and lung metastases led to progressive deterioration, which is a common complication due to widespread disease expansion.

Other treatments received by the patient mainly included subsequent lines of hormonal therapy, radiotherapy and chemotherapy with antineoplastic agents standard treatments in the management of HRPC. Although reductions in PSA levels were achieved for a limited period of time, successive changes of therapy were required because of relapse and disease progression.

Given the need for new agents that do not bear a potentially high cost in terms of side effects in the management of HRPC patients, lenalidomide is proposed as an interesting option.

\section{Conclusion}

In conclusion, the present case report presents new evidence of the potential of lenalidomide to provide clinical benefits to HRPC patients because of its antitumoral activity and lack of toxicity; the use of lenalidomide is supported in this patient population for delaying disease progression. 
Table 1. Treatment and response

\begin{tabular}{|c|c|c|c|c|}
\hline Date & $\begin{array}{l}\text { Prostate cancer } \\
\text { treatment }\end{array}$ & $\begin{array}{l}\text { Initial PSA } \mathrm{r} \\
\mathrm{ng} / \mathrm{ml}\end{array}$ & $\begin{array}{l}\text { Final PSA } \\
\mathrm{ng} / \mathrm{ml}\end{array}$ & Clinical observations \\
\hline Aug/99-Jan/08 & $\mathrm{RT} / \mathrm{CAB}$ & 19.7 & 12 & $\begin{array}{l}\text { PSA nadir } 0.1 \mathrm{ng} / \mathrm{ml} \\
\text { Bone metastases (CT) }\end{array}$ \\
\hline Jan/08-Apr/08 & $\mathrm{CAB}$ & 12 & 37 & Castration testosterone levels \\
\hline Apr/08-Jun/08 & Androcur & 37 & 64 & Bone metastases (CT) \\
\hline Jun/08-Aug/08 & Taxotere/Pred & 64 & 57 & Bone metastases (CT) \\
\hline Oct/08-Nov/08 & Oxi/Cap & 57 & 233 & \\
\hline Nov/08-Mar/09 & Fulvestrant & 203 & 321 & Bone metastases (CT) \\
\hline Mar/09-Aug/09 & Sunitinib & 321 & 749 & \\
\hline Aug/09-Sep/09 & Vin/adri/estra/keto & 749 & 1,146 & $\begin{array}{l}\text { Clinical deterioration } \\
\text { Intense pain (final PS 2) }\end{array}$ \\
\hline Oct/09 & Antalgic RT & & & Bone metastases (CT) \\
\hline Nov/09-May/10 & Lenalidomide & 1,146 & 893 & $\begin{array}{l}\text { Clinical improvement } \\
\text { No hematologic toxicity }\end{array}$ \\
\hline May/10-Jul/10 & Estracyt & 1,146 & $>5,000$ & No response \\
\hline Oct/10 & & & & $\begin{array}{l}\text { Lymph node, liver and lung } \\
\text { metastases } \\
\text { Progressive deterioration and } \\
\text { death }\end{array}$ \\
\hline
\end{tabular}

$\mathrm{RT}=$ Radiation therapy $\mathrm{CAB}=$ combined androgen blockade therapy; Pred = prednisone; $0 \mathrm{xi}=$ oxaliplatin; Cap = capecitabine; Vin/adri/estra/keto = vinblastine-Adriamycin-estramustineketoconazole.

\section{References}

1 Jemal A, Siegel R, Ward E, et al: Cancer statistics, 2009. CA Cancer J Clin 2009;59:225-249.

$\checkmark 2$ Hamberg P, Verhagen PC, de Wit R: When to start cytotoxic therapy in asymptomatic patients with hormone refractory prostate cancer? Eur J Cancer 2008;44:1193-1197.

-3 Sternberg CN: Systemic chemotherapy and new experimental approaches in the treatment of metastatic prostate cancer. Ann Oncol 2008;19(suppl 7):vii91-vii95.

4 Halabi S, Small EJ, Kantoff PW, et al: Prognostic model for predicting survival in men with hormonerefractory metastatic prostate cancer. J Clin Oncol 2003;21:1232-1237.

5 Lu L, Schafer P, Bartlett JB: Inhibition by lenalidomide of growth factor and hypoxia-induced signaling in endothelial and epithelial tumor cells, and effects within the tumor cell microenvironment. Proceedings of the Annual Meeting of the American Society of Clinical Oncology 2009, Abstract e14620.

-6 Zhu D, Corral LG, Fleming YW, et al: Immunomodulatory drugs Revlimid ${ }^{\circledR}$ (lenalidomide) and CC-4047 induce apoptosis of both hematological and solid tumor cells through NK cell activation. Cancer Immunol Immunother 2008;57:1849-1859.

7 Henry J, Lu L, Adams M, et al: Lenalidomide enhances the anti-cancer activity of docetaxel in in vitro and in vivo models of prostate cancer. American Association for Cancer Research 2010, Poster 28468. 
8 Garcia JA, Triozzi P, Smith S, et al: Phase I/II study of lenalidomide and GM-CSF in hormone refractory prostate cancer (HRPC). Proceedings of the ASCO Prostate Cancer Symposium 2007, Abstract 229.

9 Moss RA, Mohile SG, Shelton G, Melia J, Petrylak DP: A phase I open-label study using lenalidomide and docetaxel in androgen independent prostate cancer (AIPC). Proceedings of the ASCO Prostate Cancer Symposium 2007, Abstract 89.

10 Pagliaro LC, Tannir NM, Tu S, et al: A modular phase I study of lenalidomide and paclitaxel in metastatic castration-resistant prostate cancer with prior taxane therapy. J Clin Oncol 2008;26(suppl):Abstract 13545.

11 Garcia JA, Triozzi P, Elson P, et al: Clinical activity of ketoconazole and lenalidomide in castrate progressive prostate carcinoma (CPPCA): preliminary results of a phase II trial. J Clin Oncol 2008;26(suppl):Abstract 5143.

12 Petrylak DP, Resto-Garces K, Tibyan M, et al: A phase I open-label study using lenalidomide and docetaxel in castration-resistant prostate cancer. J Clin Oncol 2009;27(suppl):15s:Abstract 5156.

13 Nabhan C, Tolzien K, Kelby SK, et al: Lenalidomide (Revlimid ${ }^{\circledR}$ ) has single-agent activity in chemotherapy-naive castration-resistant prostate cancer (CRPC). American Society of Clinical Oncology, Genitourinary Cancer Symposium Meeting 2010, Poster.

14 Lestingi TM, Tolzien K, Kelby SK, et al: Safety and activity of lenalidomide (LEN) in elderly patients (pts) with chemotherapy-naive, castration resistant prostate cancer (CRPC). Proceedings of the Annual Meeting of the American Society of Clinical Oncology 2010, Abstract e15125.

15 Mathew P, Tannir N, Tu SM, et al: A modular phase I study of lenalidomide and paclitaxel in metastatic castration-resistant prostate cancer following prior taxane therapy. Cancer Chemother Pharmacol 2010;65:811-815.

16 Dahut WL, Aragon-Ching JB, Woo S, et al: Phase I study of oral lenalidomide in patients with refractory metastatic cancer. J Clin Pharmacol 2009;49:650-660.

17 Zhu D, Corral LG, Fleming YW, et al: Immunomodulatory drugs Revlimid (lenalidomide) and CC-4047 induce apoptosis of both hematological and solid tumor cells through NK cell activation. Cancer Immunol Immunother 2008;57:1849-1859.

18 Bubendorf L, Schöpfer A, Wagner U, et al: Metastatic patterns of prostate cancer: an autopsy study of 1,589 patients. Hum Pathol 2000;31:578-583. 